\title{
The Validity and Reliability Study of the Scale of the Perceived Sociability of Online Learning Environments
}

\author{
Salih BARDAKCI*
}

\begin{abstract}
The aim of this study is to adapt The Perceived Sociability Scale of Computer-Supported Collaborative Learning Environments developed by Kreijns, Kirschner, Jochems and Buuren (2007) to online learning environments in Turkey. The original scale is in English and includes 10 items. Firstly, the original scale was translated into Turkish, and experts' critics were obtained. Afterwards, both the English and Turkish forms were administered to students $(n=31)$ of Başkent Universty Computer Education and Instructional Technologies (CEIT) Department in a one-week interval in order to determine the equivalency of these two forms. The construct validity studies were carried out on 94 CEIT students attending to Ankara, Hacettepe and Başkent Universities. Results showed that the Turkish version has one factor and consisted of 10 items like the original scale. The Cronbach Alpha internal consistency coefficient was also obtained as .82 .
\end{abstract}

Key Words: Online learning environments, Perceived Sociability Scale

\footnotetext{
* Research Assistant. Ankara Universty, Faculty of Educational Sciences, Department of Computer Education \& Instructional Technology. sbardakci@education.ankara.edu.tr
} 


\section{SUMMARY}

Purpose and Significance: The aims of this study are to adapt the perceived sociability scale, developed by Kreijns, Kirschener, Jochems and Buuren, into Turkish and examine validity and reliability properties. The concept of sociability was introduced in early 20 'th century to define the quality of the individual's relations within his/her social environment. In other words the environment's wideness with regard to social interaction (Simmel, 1949). This concept was firstly used as the dimension of online learning climate by Preece (2000) so as to describe the social and technical structures that support the social interaction and shared aims. Nowadays, the dimensions of online learning groups are handled into two categories. The first one is configuration the possibilities of sociability and this process is related to the politics which lead to common goals, participants and activities of the community (Lazar and Preece, 2003:127-128). The second one is the perception of the participants about the composed sociability elements and with respect to this aspect, the main determinative of interaction intensity in community are the perceptions of participants regarding elements than the elements of sociability (Kreijns at all, 2007). The studies propound that participants perceptions about sociability elements in community are the basic element, effects the levels of enjoyment being in a community, the confidence and attitudes to the community, the conformance to the community, social presence, the levels of active attendance and the performance of learning mission. This condition requires that perceived sociability should be defined and developed.

Method: This research was designed based on single-scanning model. The data was gathered from the students, attending Computer Education and Instructional Technologies Program in Ankara, Hacettepe and Başkent Universities. The translated version of the scale was examined by eight experts, one of them was Turkish Language expert, the others were educational technologist. 31 students were participated for the equivalency of the original scale and then Turkish version of the scale was given to 94 students. Exploratory factor analyses were conducted to examine the construct validity. Kaiser-Mayer-Olkin (KMO) score was .79 and Barlett score was 303.48 with respect to the significance levels $(p=.00)$. So, the data were adequate to exploratory factor analyses. The data were analyzed with Unrotated Principal Component Analysis. The all items discriminations were determined by independent $t$ test. For all items of the scales' factor loading values, the total-item correlations and common factor loading values were calculated. Moreover, factor loading values of the Turkish version and the original version of the scales were presented comparatively. The 
appropriateness of the model gained from exploratory factor analysis was examined by confirmatory factor analysis and the goodness of fit indexes were discussed.

Results: There is a significant correlation between the original and Turkish version of the scale in the equivalency was .78 level $(p=.00)$. In the construct validity studies, the ten items are included in the Turkish version of a scale were collected to one factor. The perceived sociability scale-Turkish version accounting for $40.11 \%$ of the total variance. Factor loading of the items ranged from .48 to .84 , from .23 to .70 for common factor variance and from .37 to .74 for total-item correlations. The internal consistency coefficient of the scale (Cronbach alpha) was .82. The value of goodness of fit indexes from confirmatory factor analysis are $\left[X^{2}(94)=67.92, \mathrm{p}<.01\right.$; $X^{2} / d f=2.00 ; \mathrm{GFI}=.87 ; \mathrm{AGFI}=.79 ; \mathrm{CFI}=.92 ; \mathrm{NFI}=.85 ; \mathrm{RMSEA}=.10 ; \mathrm{S}-$ $\mathrm{RMR}=.08 ; \mathrm{IFI}=.92]$. These values show the appropriateness of the model.

Discussion and Conclusions: The findings of this study indicated that Turkish version of the perceived sociability scale could be used to support the sociability dimensions of on-line learning communities in Turkey. Explained variance was acceptable (Büyüköztürk, 2006: 125). The perceived sociability scale was a valid and reliable instrument to measure sociability in Turkey with respect to internal consistency and total-item correlations. 


\title{
Çevrimiçi Öğrenme Ortamında Algılanan Sosyalleşme Ölçeğinin Geçerlik ve Güvenirlik Çalışması
}

\begin{abstract}
Salih BARDAKCI*
ÖZ. Bu araştırmanın amacı Kreijns, Kirschner, Jochems ve Buuren (2007) tarafından bilgisayar destekli ortaklaşa öğrenme ortamlarına yönelik olarak geliştirilen Algılanan Sosyalleşme Ölçeği'nin Türkçeye ve çevrimiçi öğrenme ortamlarına yönelik uyarlamasını gerçekleştirmektir. Çevrimiçi Öğrenme Ortamında Algılanan Sosyalleşme Ölçeği tek faktör altında toplanmış beşli Likert tipinde 10 önermeden oluşmaktadır. Uyarlama sürecinde ölçek Türkçeye çevrilmiş ardından dil ve eğitim teknolojisi alanında uzman yedi öğretim üyesinin değerlendirmeleri alınmıştır. Dilsel eşdeğerlik çalışmaları Başkent Üniversitesi Eğitim Fakültesi Bilgisayar ve Öğretim Teknolojileri Eğitimi Bölümü’nde (BÖTE) öğrenim görmekte olan 31 öğrencinin katılımıyla gerçekleştirilmiştir. Yapı geçerliği çalışmaları Ankara, Hacettepe ve Başkent Üniversitesi BÖTE bölümlerinde öğrenim görmekte olan ve çevrimiçi öğrenme deneyimine sahip 94 öğrenci üzerinde yürütülmüştür. Açımlayıcı ve doğrulayıc1 faktör analizleri sonucunda Türkçe ölçeğin özgün formundaki yapısını koruduğu görülmüştür. Türkçe forma ilişsin Cronbach Alfa iç tutarlılık katsayısı .82 olarak belirlenmiş̧ir.
\end{abstract}

Anahtar Sözcükler: Çevrimiçi öğrenme ortamı, Algılanan Sosyalleşme Ölçeği

\footnotetext{
* Araştırma Görevlisi. Ankara Üniversitesi, Eğitim Bilimleri Fakültesi, Bilgisayar ve Öğretim Teknolojileri Eğitimi Bölümü. sbardakci@education.ankara.edu.tr
} 


\section{GİRIŞ}

Sosyalleşme (sociability), çevrimiçi öğrenme ortamlarının sosyal etkileşimin oluşturulması ve desteklenmesine ilişkin tasarım, uygulama ve geliştirme boyutu olarak tanımlanmaktadır (Farnham, Melora, Zaner ve Cheng, 2001; Kreijns, Kirshner, Jochems ve Buuren, 2007; Preece, 2001a). Kavram 20. yüzyılın başlarında bireyin sosyal çevresiyle kurduğu ilişkiler bütününün niteliğini ifade etmek üzere ortaya atılmıştır. $\mathrm{Bu}$ yaklaşıma göre, insan doğası gereği sosyaldir, diğer bireylerle etkileşim gereksinimi içerisindedir. $\mathrm{Bu}$ gereksinimin temelinde bireysel yetilerini ortaya koyarak doyum sağlama isteği bulunmaktadır. Bireysel yetiler birey yalnızken anlamlı değildirler, bir topluluk içerisinde değer kazanmakta ve doyum sağlamaktadırlar (Simmel, 1949). Sosyalleşme bireyin içerisinde bulunduğu ortama ilişkin bir yaklaşımdır ve ortamın ve grubun sosyal etkileşime yönelik genişliğini ifade etmektedir (Ritzer, 1992).

Seksenli yılların ortalarından itibaren bilişim teknolojilerinin sosyal etkileşime olanak sağlayacak biçimde gelişmesi çevrimiçi topluluk kavramını ortaya çıkarmıştır. Çevrimiçi topluluk ortak ilgilere, paylaşılan amaçlara ve kaynaklara sahip bir grup kullanıcının bilgisayar tabanlı bir ortam üzerinden iletişim kurması olarak tanımlanmaktadır (Lazar ve Preece, 2003: 128). Rheingold 1987-1988 yıllarında San Francisco'da oluşturulan ve ilk çevrimiçi topluluk olarak nitelendirilen WELL sistemi kullanıcıları üzerinde gerçekleştirdiği araştırmaları sonucunda, böyle bir topluluğun oluşması ve yaşamını sürdürmesinde teknolojik alt yapının ötesinde katılımcılar ve sosyal etkileşim desteği unsurlarının bulunduğunu ortaya koymuştur. Buna göre çevrimiçi topluluk, yeterince insanın yeterli bir sosyal etkileşim alanında yarattıkları kültürel katılım sürecidir (Rheingold, 1994: 57-58). İnternet temelli etkileşim teknolojilerinin gelişmesi çevrimiçi topluluklarda zamandan ve mekândan bağımsızlık gibi temel değişimlerin yanı sıra katılımcıların birbirlerini yüz yüze tanımadıkları çok geniş ve dağınık bir topluluk deseni yaratmıştır (Nie, 2001). Bu dağınıklık katılımcıların fiziksel olarak bir arada bulunduğu ortamlarda ortak amaçlar dışında gerçekleştirilen, bağlılık ve güven duygularının oluşumunda önemli katkılar sağlayan birtakım sosyal süreçlerin çevrimiçi ortamlarda da oluşturulması gerekliliğini beraberinde getirmiştir. Sproul ve Faraj (1997: 38; Akt. Kreijns ve diğerleri, 2007) böyle bir yapıda topluluğa katılımda temel esaslar olarak, ortak ilgilerin yanında bireylerin birbiriyle sohbet etme, birbirilerini dinleme ve bu etkinliklerden zevk alma durumları üzerinde durmaktadırlar.

Sosyal etkileşim olanaklarının genişliği, çevrimiçi öğrenme topluluklarında verimlilik ve sürekliliğin temel belirleyicisi olarak ele 
alınmaktadır (Kreijns ve diğerleri, 2007; Preece, 2003). Buna göre öğrenme topluluklarında gerçekleşen biliş ve anlamlandırma süreçlerinin ana etkenleri; paylaşılan amaçlar, sosyal etkileşim yoğunluğu ve topluluğun sosyokültürel yapısıdır (Barab, Makinster, Moore ve Cunningham, 2001; Kreijns ve diğerleri, 2007). Bu durum çevrimiçi öğrenme topluluklarının temel bir sorunu olarak güçlü bir sosyal etkileşim sürecinin yapılandırılmasını karşımıza getirmektedir (Kreijns ve diğerleri, 2007; Preece, 2001a; 2001b). Burada ele alınan sosyal etkileşim hem topluluğun ortak amaçlarına hem de bunların dişında günlük yaşama ilişkin olarak gerçekleştirilen etkileşimi kapsamaktadır. Habaugh'a göre (1997) sosyal etkileşimin yeterince gelişmediği ortamlarda grup eylemleri etkisiz kalmakta, katılımcıların bu eylemlere ilişkin dikkatleri düşmekte, katılımcılar arasında iyi anlaşılamama ya da yanlış anlaşılma sorunları yaşanmakta, topluluk hissi ve bağlllık duyguları gelişememektedir. Kreijns ve diğerleri (2007) bu duruma neden olarak ortam tasarımcılarının daha çok teknik alt yapıya odaklanıp, sosyal alt yapıyı ihmal etmelerini göstermektedirler.

Sosyalleşme kavramı çevrimiçi öğrenme ortamlarının bir boyutu olarak ilk kez Preece (2000) tarafından sosyal etkileşimi ve paylaşılan amaçları destekleyen sosyal ve teknik yapıları tanımlamak amacıyla kullanılmıştır. Barab ve diğerleri (2001) bu teknik ve sosyal alt yapı unsurlarını ortamın sosyoteknik boyutu olarak ele almaktadırlar. Farklı yaklaşımlar incelendiği zaman bir grup bilim insanının (Barab ve diğerleri, 2001; Farnham ve diğerleri, 2001; Lazar ve Preece, 2003: 127-128; Preece, 2000; 2001a; 2001 b; 2003) sosyalleşme sürecinin sosyal ve teknik alt yapısına; diğer bir grubun da bu alt yapı olanaklarının katılımcılar tarafından nasıl algılandığına ve bu algilamanın topluluk üzerindeki etkilerine (Donath, 1997; Kreijns, Kirschner ve Jochems, 2002; Kreijns ve diğerleri, 2007) odaklandıkları görülmektedir.

Sosyal ve teknik alt yapıya odaklanan yaklaşımın öncülerinden Preece'e (2000; 2007) göre bir çevrimiçi öğrenme topluluğunun başarısını belirleyen iki unsur söz konusudur. Bunlar, katılımc1-arayüz etkileşimini düzenleyen kullanışlılık ve katılımcı-grup etkileşimini düzenleyen sosyalleşmedir. $\mathrm{Bu}$ anlayışta sosyalleşme; topluluğun amaçları ile katılımcıların ilgi ve gereksinimleri doğrultusunda gerçekleştirilmek istenen sosyal etkileşim düzeyinin belirlenmesini, gerekli politikaların oluşturulmasını, yazılımın geliştirilmesini ve uygulamaları kapsayan bir süreçtir (Farnham ve diğerleri, 2001; Preece, 2000; 2001a). Preece (2000; 2001a; 2001b) ve Lazar ve Preece (2003) sosyalleşme sürecinde üç temel bileşen üzerinde durmaktadırlar. 
Bunlar; paylaşılan amaçlar, katılımcılar ve etkileşimi yönlendiren politikalardir.

Sosyalleşmenin algılanmasına odaklanan yaklaşım sosyalleşme kaynaklarına yönelik katılımcı algılarının, topluluğun sosyal etkileşim yoğunluğu, sosyal etkileşim alanı (social space) ve sosyal buradalık (social presence) süreçleriyle ilişkilerini irdelemektedir. Kreijns (2004) ve Kreijns ve diğerlerine (2007) göre sosyalleşmeye ilişkin teknik alt yapı, politika ve ilkeler ne kadar güçlü olursa olsun, topluluktaki sosyalleşme sürecinin asıl belirleyicisi katılımciların bu yapılardan haberdar olma dereceleri, dolayısıyla bu yapılara ilişkin algılamalarıdır. Bu açıdan sosyalleşme güven, bağl1lık ve topluluk hissini içeren güçlü bir sosyal etkileşim alanının oluşumunu kolaylaştıran ve katılımcılar tarafindan algılanan bir kapsam olarak nitelenmektedir (Donath, 1997; Kreijns ve diğerleri, 2007). Donath'a göre (1997) bir çevrimiçi topluluğun yaşamına devam edebilmesi, kullanıcıların, etkinlikleri ve ilişkileri kapsayan sosyal deseni algılayabilmelerine ve bu yapıyı kullanarak bir topluluk kültürü geliştirebilmelerine bağlıdır.

Sosyalleşmenin kaynă̆ında ortamda bulunan sosyal etkenler (social affordances) yatmaktadır (Volet ve Wosnitza, 2004). Sosyal etkenler, çevrimiçi öğrenme ortamlarında üyelerin birbirileri hakkında bilgi sahibi olmalarına ve her bir üyeye ilişkin topluluk tarafından paylaşılan kanılar (güvenilir, kızgın, anlayışlı vb.) geliştirilmesine fırsat sağlayan yapılardır. $\mathrm{Bu}$ etkenler sayesinde üyeler birbirilerini yakından tanımakta, birbirlerinin amaçlarından haberdar olmakta, karşılıklı güven duyguları gelişmekte, topluluğa ilişkin bir bilgi ve deneyim birikimi gerçekleşmektedir. Bu bilgi topluluğun farkındalık bilgisi olarak nitelenmekte ve özel bir dili, norm ve gelenekleri olan topluluk kültürünü doğurmaktadır (Kreijns ve diğerleri, 2007). Kalaitzakis, Dafoluas ve Macaulay'a göre (2003) önemli iki sosyal etken ortamda istenildiği zaman anlık sohbet gerçekleştirebilme olanağ1 ve topluluğun farklılıkları kabul etme (1lımlıl1k) derecesidir.

Kreijns (2004: 7) sosyalleşmeyi ele alırken yoğun olarak sosyal etkileşim alanı kavramı üzerinde durmaktadır. Sosyal etkileşim alanı, katılımcılar tarafından paylaşılan inançlar, değerler, normlar, kabuller, kurallar, idealler ve üstlenilen rollerin meydana getirdiği ilişkiler ağıdır ve sosyalleşme de ortamın bu alanı oluşturabilme ya da oluşumunu kolaylaştırabilme yetisidir. İyi yapılandırılmış bir sosyal etkileşim alanında etkili çalışma ilişkileri, güçlü bir topluluk hissi, güven, sayg1 ve bağl1lık duyguları ve yüksek bir doyum söz konusudur. Sosyal etkileşim alanının gücü, topluluğun sosyal etkileşim yoğunluğunu, etkileşimin niteliğini ve devamlılığını belirlemektedir (Kreijns ve diğerleri, 2002). Bu yaklaşımda 
sosyalleşme ile sosyal buradalık süreçleri arasında da yakın bir ilişkiden söz edilmektedir (Kreijns, 2004: 7). Sosyal buradalık (toplumsal buradalık; Öztürk, 2008) etkileşim esnasında diğer bireylerin dikkat ve ilgilerini çekebilme gücü ve bireyler arası ilişkilerdeki dikkat çekiciliklerin toplam sonucu olarak tanımlanmaktadır. Kısaca, katılımcıların ortamdaki diğer katılımcıları gerçek bireyler olarak algılayabilmelerini ifade etmektedir (Kreijns, 2004: 7). Tu'ya göre (2000) sosyal buradalık çevrimiçi öğrenme topluluklarında sosyal etkileşimin, sosyal etkileşim de öğrenmenin temel koşuludur.

Kreijns' e göre $(2004,7-8)$ bir çevrimiçi öğrenme topluluğunun temel amacı güçlü bir sosyal etkileşim alanı oluşturmaktır. Bu amaca yönelik başarıya etki eden üç bileşenden söz edilebilir. Bunlar ortamın sosyal etkileşime yatkınlığını belirleyen sosyalleşme, katılımcıların sosyal etkileşime yatkınlıklarını belirleyen sosyal buradalık ve öğrenme etkinliklerinin sosyal etkileşime yatkınlıklarını belirleyen öğretim yöntem ve teknikleridir. Katılımcıların sosyalleşmeye ilişkin algıları hem sosyal buradalık düzeylerini hem de sosyal etkileşime yatkınlıklarını dinamik biçimde etkilemektedir (Kreijns, 2004: 8; Kreijns ve diğerleri, 2007). Bu yaklaşım Şekil 1.'de Kreijns'in 'Sosyalleşme Süreciyle İlişkili Değişkenler Modeli" ile sunulmaktadır (Kreijns, 2004: 8).

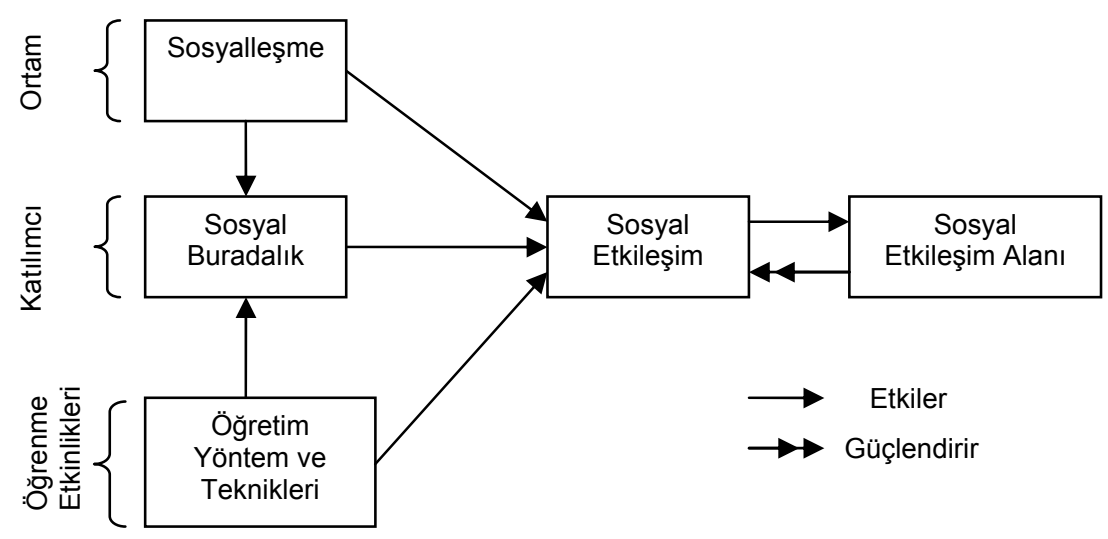

Şekil 1. Sosyalleşme Süreciyle İlişkili Değişkenler Modeli (Karel Kreijns, 2004. Sociable CSCL Environments Social Affordances, Sociability, and Social Presence, s.8'den alınmıştır.) 
Katılımcıların sosyalleşme unsurlarına yönelik algılarının çevrimiçi öğrenme toplulukları üzerine etkilerini inceleyen çeşitli araştırmalar bulunmaktadır. Hassanein ve Head (2004) üç farklı gruba farklı düzeylerde sosyalleşme olanakları sundukları araştırmalarında katılımcıların ortamın sosyalleşme düzeyine ilişkin algıları arttıkça topluluğun sıcaklık ve samimiyetine ilişkin düşüncelerinin ve buna bağlı olarak öğrenme başarımlarının (performanslarının) arttığını ortaya koymaktadırlar. Aynı araştırmaya göre katılımcıların topluluğun sosyalleşmesine ilişkin algıları sosyal buradalık düzeyini, sosyal buradalık düzeyi toplulukta bulunmaktan zevk alma ve güven duygusu oluşumunu, bu unsurlar da topluluğa ilişkin olumlu tutum gelişimini etkilemektedirler. Volet ve Wosnitza (2004) farklı kültürlerden katılımcıların bulunduğu bir çevrimiçi öğrenme topluluğunda sosyal etkenleri öğrenme etkinlikleri başlamadan işe koştukları araştırmalarında katılımcıların öğrenme etkinliklerinden önce topluluğun sosyal olanaklarıyla tanışmaları ve bunlara ilişkin algılar geliştirmelerinin öğrenme firsatlarının keşfedilmesini kolaylaştırdığını ayrıca sosyal buradalık hissi ve katılım durumlarını artırdığını gözlemlemişlerdir. Barab ve diğerleri (2001) stajyer ve uzman öğretmenlerin yer aldığ bir çevrimiçi öğrenme topluluğu üzerinde gerçekleştirdikleri araştırmalarında topluluğun paylaşımları doğrultusunda geliştirdiği ortak kültür ve bu kültüre ilişkin algılamaların meydana getirdiği farkındalığın topluluğa yeni katılan stajyer öğretmenlerin uyum sağlama süreçlerini önemli ölçüde hızlandırdığını belirlemişlerdir.

Araştırmalar katılımcıların çevrimiçi öğrenme topluluklarındaki sosyalleşme unsurlarına yönelik algılamalarının toplulukta bulunmaktan zevk alma düzeyleri, topluluğa yönelik güven duyguları ve tutumları, topluluğa uyum sağlama, sosyal buradalık ve buna bağlı olarak etkin katılım düzeylerini ve öğrenme görevlerine yönelik başarılarını etkileyen temel bir unsur olduğunu ortaya koymaktadır. Çevrimiçi öğrenme ortamlarının ülkemizde de yaygınlaşmaya başlaması, bu ortamlara yönelik doyum, güven, bağl11ık, uyum hisleri ve etkin katılım durumları gibi unsurları, dolayısıyla sosyalleşme boyutunu bir ilgi alanı olarak öne çıkarmaktadır. Bu durum algılanan sosyalleşmeyi belirlemeye dönük dilimize ve kültürümüze uygun ölçme aracı geliştirme gereksinimini beraberinde getirmektedir. Araştırmada bu gereksinimden hareketle Kreijns, Kirshner, Jochems ve Buuren (2007) tarafından bilgisayar destekli ortaklaşa öğrenme ortamlarına yönelik olarak geliştirilen Algılanan Sosyalleşme Ölçeği’nin kültürümüze yönelik uyarlama çalışmalarının gerçekleştirilmesi amaçlanmaktadır. Bilgisayar destekli ortaklaşa öğrenme deneyimine sahip yeterli bir çalışma grubuna 
erişilemediğinden uyarlama çalışmaları çevrimiçi öğrenme topluluklarına yönelik olarak gerçekleştirilmiştir.

\section{YÖNTEM}

Araştırma Modeli ve Grubu: Araştırma genel tarama modelindedir. Araştırma verileri Ankara Üniversitesi Eğitim Bilimleri Fakültesi, Hacettepe Üniversitesi Eğitim Fakültesi ve Başkent Üniversitesi Eğitim Fakültesi Bilgisayar ve Öğretim Teknolojileri Eğitimi (BÖTE) Bölümleri’nde öğrenim görmekte olan ve 2007-2008 öğretim yılı bahar döneminde çevrimiçi öğrenme deneyimi yaşayan lisans düzeyinde 94 öğrenciden elde edilmiştir. Araştırma grubunun üniversitelere ve sınıflara göre dağılımları Tablo 1'de sunulmaktadır.

Tablo 1. Katılımcıların Üniversitelerine ve Sinıflarına Göre Dăğlımları

\begin{tabular}{llll}
\hline Üniversite & Sinıf & $f$ & $\%$ \\
\hline Ankara Üniversitesi & 3 & 26 & 27.66 \\
Hacettepe Üniversitesi & 3 & 37 & 39.36 \\
Başkent Üniversitesi & 2 & 31 & 32.98 \\
Toplam & & $\mathbf{9 4}$ & $\mathbf{1 0 0 . 0 0}$ \\
\hline
\end{tabular}

Araç ve Uygulama: Çevrimiçi Öğrenme Ortamlarında Algılanan Sosyalleşme Ölçeği'nin (ÇASÖ) İngilizce özgün formuna erişildikten sonra (Kreijns ve diğerleri, 2007), e-posta aracılığıyla ölçek geliştiricilerinden uyarlama çalışmaları için gerekli izinler ve istatistiksel bilgiler alınmıştır. Özgün ölçek tek faktör altında toplanmış beşli Likert tipinde 10 maddeden oluşmaktadır. Tüm maddeler toplam puana olumlu yönde katkı sağlamaktadırlar. Ölçekten elde edilebilecek en yüksek puan 50, en düşük puan 10'dur. Geliştirme çalışmaları Hollanda Açık Üniversitesi'nin farklı programlarında öğrenim gören 93 katılımcı üzerinde gerçekleştirilmiştir. Ölçeğe ilişkin Cronbach Alfa iç tutarlılık katsayısı .92 olarak hesaplanmıştır.

Uygulama sürecinde öncelikle özgün ölçek araştırmacı tarafından hedef dil olan Türkçeye çevrilmiş ve bir Türkçe uzmanının görüşü alınarak özgün anlamların dilimizde daha anlaşılır biçimde ifade edilebilmesi için gerekli düzenlemeler yapılmıştır. Ardından özgün ve Türkçe ölçek bir arada eğitim teknolojileri alanında uzman ve her iki dile hâkim yedi öğretim üyesinin görüşüne sunulmuştur. Uzmanlardan gelen öneriler doğrultusunda yapılan düzenlemelerin ardından iki ölçek arasındaki dilsel eşdeğerlik geçerliğinin belirlenmesi için İngilizce ve Türkçe formlar bir hafta arayla Başkent Üniversitesi BÖTE Bölümü 2. sınıfında öğrenim görmekte olan; her iki dilde 
yetkin ve çevrimiçi öğrenme deneyimine sahip 31 kişilik bir gruba uygulanmıştır. Ardından ÇASÖ 94 kişilik araştırma grubu üzerinde uygulanmıştır.

Analiz: ÇSAÖ'nün yapı geçerliğini test etmek amacıyla temel bileşenler analizi (PCA) yöntemine dayalı açımlayıcı faktör analizinden ve SPSS 11.00 paket programından yararlanılmıştır. Alanyazın irdelendiğinde faktör analizi çalışmalarında kullanılan ölçekteki madde sayısının 10 katı oranında bir örnekleme erişilmesinin tavsiye edildiği görülmektedir (Büyüköztürk, 2002). 10 maddelik ölçeğin yapı geçerliğini test etmek üzere 94 katılımcıya ulaşılarak bu oran sağlanmaya çalışılmıştır. Araştırma grubunun faktör analizine uygunluğunu ortaya koymak üzere Kaiser-MayerOlkin (KMO) değeri hesaplanmıştır. Örneklem büyüklüğü ve maddeler arasındaki korelasyonun faktör analizine uygunluğunu ortaya koyan bu değer için .60 ve üzerinin yeterli kabul edildiğini belirtilmektedir (Büyüköztürk, 2006: 126; Kline, 1994: 75). Çalışmada araştırma grubuna ilişkin KMO değeri .79 olarak belirlenmiştir. Dağılımın normallik düzeyinin faktör analizinin koşularını karşılama durumu Barlett Testi ile incelenmiş (Büyüköztürk, 2006: 126; Kline, 1994: 75) ve elde edilen Bartlett değerinin anlamlı olduğu görülmüştür $\left[X_{(45)}^{2}=303.48, \mathrm{p}<.01\right]$. Bu bulgular sonucunda, araştırma grubunun açımlayıcı faktör analizine uygun olduğuna karar verilmiştir.

Ölçekte yer alan her bir maddenin algılanan sosyalleşmenin açıklanmasına katkısını ortaya koymak için faktör yük değerleri, maddetoplam korelâsyonları ve ortak faktör varyansına katkıları hesaplanmış, ayrıca Türkçe ve özgün ölçekten elde edilen faktör yük değerleri karşılaştırmalı olarak sunulmuştur. Maddelerin ayırt etmedeki yeterliliğini belirlemek için üst ve alt \%27'lik grupların madde puanları arasındaki farkların anlamlılı̆̆ bağımsız $t$-testi ile incelenmiştir.

Yap1 geçerliği çalışmalarıyla ortaya konulan faktör yapısının uygunluğunu belirlemek üzere doğrulayıcı faktör analizlerinden yararlanılmış; bu amaçla en yüksek olabilirlik yöntemine dayalı olarak çalışan LISREL 8. 30 paket programı kullanılmıştır. Bu süreçte öncelikle açımlayıcı faktör analiziyle ortaya konan ve kuramsal olarak temellendirilebilinen faktör yapısı öngörülen model olarak tanımlanmış; ardından araştırma verilerinin bu modele ne derecede uygun bir yapı gösterdiği doğrulayıcı faktör analizi ile elde edilen uyum iyiliğgi indeksleriyle incelenmiştir. 


\section{BULGULAR VE YORUM}

Dilsel eşdeğerlik çalışması sonucunda, özgün ve Türkçe ölçek arasında yüksek düzeyde, anlamlı bir korelâsyon olduğu görülmüştür [ $\mathrm{r}=.78 ; \mathrm{p}<.01]$. Buna göre, iki ölçek arasında olumlu yönde ve iyi derecede anlamlı bir ilişki söz konusudur.

\section{Açımlayıcı Faktör Analizi}

Faktör yapısını ortaya koymak için öncelikle döndürülmemiş temel bileşenler analizi gerçekleştirilmiştir. Faktör sayısının belirlenmesinde Kaiser-Guttman ilkesi uyarınca özdeğerleri 1'den büyük faktörlerin incelenmesi yoluna gidilmiş; faktör özdeğerlerine ilişkin çizgi grafiği ve açıkladıkları varyans oranları incelenmiştir (Zwick ve Velicer, 1986). Ölçek, özdeğerleri 1'den büyük iki faktör yapısına sahiptir. Bu faktörlerden ilkinin özdeğeri 4.01'dir ve açıklanan toplam varyansa \%40.11 düzeyinde bir katk1 sağlamaktadır. İkinci faktörün özdeğeri ise 1.42 'dir ve açıklanan toplam varyansa katkıs1 \%14.15 düzeyindedir. $\mathrm{Bu}$ değerler tek başlarına ele alındığında ölçeğin iki faktörlü bir yapı gösterebileceği düşünülmektedir. Ancak alanyazın incelendiğinde bu değerlerin tek başına incelenmesinin gerçekte var olandan fazla sayıda faktör üretilmesine yol açabileceği; faktör yapılarına karar verebilmek için bunların yanında dikkate alınması gereken temel bir ölçütün ortaya konulan çözümün kuramsal olarak temellenebilmesi olduğu görülmektedir (Zwick ve Velicer, 1986). Buradan yola çıkarak, daha sağlıklı karar verebilmek açısından hem iki hem de tek faktörlü yapı için temel bileşenler analizi uygulanmasına ve ortaya çıkan yapıların kuramsal olarak değerlendirilmesine karar verilmiştir.

İki faktörlü yapıya ilişkin olarak varimax dik döndürme tekniği ile gerçekleştirilen temel bileşenler analizi sonucunda binişik değer gösteren iki maddenin çıkarılmasıyla ölçek maddelerinin iki faktör yapısı altında istatistiksel olarak anlamlı biçimde toplanabildikleri görülmüştür. Ancak maddeler incelendiğinde istatistiksel olarak birbirinden ayrışan bu yapıların kuramsal olarak ayrışamadığı ve adlandırılamadığı belirlenmiştir. Bu yapıda kuramsal olarak birbiriyle ilişkili maddeler bir araya gelememekte; iki faktör altında dağılmaktadırlar. Buradan hareketle maddelere tek faktörlü çözüm sınırlaması getirilerek yeniden analize alınmalarına karar verilmiştir.

Tek faktörlü yapıya ilişkin olarak gerçekleştirilen temel bileşenler analizinde tüm maddelerin tek faktör altında anlamlı yük değerleri oluşturacak ve toplam varyansın önemli bölümünü açıklayabilecek biçimde toplanabildikleri belirlenmiştir. Şekil 2'de Faktör özdeğerlerine ait çizgi grafiği ve Tablo 2'de ölçeğin tek faktörlü yapısına ilişkin açımlayıcı faktör analizi sonuçları sunulmaktadır. 


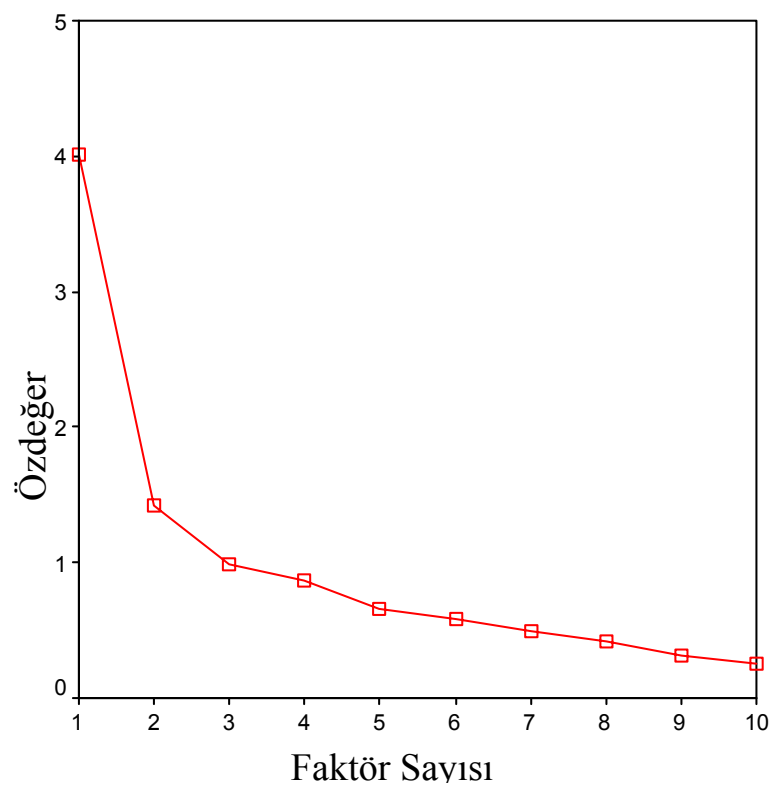

Şekil 2. Faktör Özdeğgerlerine İlişkin Çizgi Grafiği

Tablo 2. ÇASÖ Açımlayıcı Faktör Analizi Sonuçları

\begin{tabular}{lll}
\hline $\begin{array}{l}\text { Madde } \\
\text { Numaras1 }\end{array}$ & $\begin{array}{l}\text { Faktör } \\
\text { Yük Değeri }\end{array}$ & $\begin{array}{l}\text { Ortak Faktör } \\
\text { Varyans1 }\end{array}$ \\
\hline M6 & .84 & .70 \\
M5 & .72 & .52 \\
M7 & .71 & .49 \\
M10 & .63 & .40 \\
M4 & .62 & .39 \\
M3 & .60 & .36 \\
M1 & .60 & .37 \\
M8 & .55 & .30 \\
M2 & .50 & .25 \\
M9 & .48 & .23 \\
\hline
\end{tabular}

Tablo 2 incelendiğinde ölçekte yer alan 10 maddenin faktör yük değerlerinin .48 ile .84 arasında, maddelere ilişkin ortak faktör varyanslarının .23 ile .70 arasında değiştiği görülmektedir. Temel bileşenler analiziyle ortaya konan faktör yük değerleri, maddelerin faktörlerle olan ilişkilerinin gücünü; her madde için kabul edilen faktörler altında gösterdiği 
yük değerlerinin karelerinin toplamı alınarak hesaplanan ortak faktör varyansı ise ilgili maddenin diğer maddelerle birlikte ölçeğe ilişkin toplam varyansı açıklama gücünü ortaya koymaktadır (Büyüköztürk, 2006: 124134). Buradan hareketle, toplam varyansa en yüksek katkıyı .84 faktör yük değeri ve .70 ortak faktör varyansı ile 6 . maddenin, en düşük katkıyı ise .48 faktör yük değeri ve .23 ortak faktör varyansı ile 9. maddenin yapmakta olduğu ifade edilebilir. Tek faktörlü yapının açıklayabildiği toplam varyans \% 40.11 düzeyindedir. Alanyazında tek faktörlü ölçek yapılarında toplam varyansın \%30'unun açıklanması yeterli görülmektedir (Büyüköztürk, 2006: 125). Bu ölçüte dayanarak elde edilen tek faktörlü ölçek yapısı çevrimiçi öğrenme ortamlarında algılanan sosyalleşmeyi ölçmek için yeterli bulunmuştur. Ölçekte yer alan on maddenin tamamı için faktör yük değerleri .45 'in üzerinde kalmıştır. Alanyazında .45 ve üzerinde faktör yük değeri gösteren maddeler ölçekte kesinlikle tutulması gereken maddeler olarak nitelenmektedir (Büyüköztürk, 2006: 124; Kline, 2000a: 167-168). Buradan hareketle Türkçe ölçeğin tek faktör altında on maddenin tamamını içermesine karar verilmiştir.

\section{Madde Analizleri}

Ölçekte yer alan maddelerin topluluğun sosyalleşmesine ilişkin algılara yönelik ayırt ediciliklerini ortaya koymak üzere hesaplanan madde-toplam korelâsyonları ve toplam puana göre belirlenen üst ve alt \%27'lik grupların madde puanları arasındaki farkın anlamlılı̆̆ını irdeleyen bağımsız $t$-testi sonuçları Tablo 3'te sunulmaktadır.

Tablo 3. ÇASÖ Madde Analizi Sonuçları

\begin{tabular}{lll}
\hline $\begin{array}{l}\text { Madde } \\
\text { Numaras1 }\end{array}$ & $\begin{array}{l}\text { Düzeltilmiş Madde-Toplam } \\
\text { Korelâsyonları }\end{array}$ & $\begin{array}{l}\text { Üst \% 27-Alt \%27 Farkın Anlamlılık Testi } \\
\text { (Bağımsız } t \text {-testi) }\end{array}$ \\
\hline M1 & .46 & -6.63 \\
M2 & .37 & -4.22 \\
M3 & .49 & -5.91 \\
M4 & .53 & -6.25 \\
M5 & .60 & -6.73 \\
M6 & .74 & -10.95 \\
M7 & .58 & -6.78 \\
M8 & .43 & -4.24 \\
M9 & .40 & -5.04 \\
M10 & .54 & -8.35 \\
\hline p $=.000$ & &
\end{tabular}


Ölçek maddelerinin madde-toplam korelâsyonları. 37 ile .74 aralığında değişmektedir. Ayrıca, $t$-testi sonuçlarına göre tüm maddelere ait üst ve alt $\% 27^{\prime}$ lik grup madde puanları anlamlı biçimde farklılaşmaktadır $(\mathrm{p}=.00)$. Üst $\% 27^{\prime}$ lik grubun tüm maddelere ilişkin madde puan ortalamaları alt \%27'lik grubun madde puan ortalamalarından anlamlı biçimde yüksektir. Buna göre ölçekte yer alan maddeler aynı davranışı; yani çevrimiçi öğrenme topluluklarında sosyalleşmeye yönelik katılımcı algılarını ölçmekte ve farklı alg1 seviyelerindeki katılımcıları anlamlı biçimde ayırt edebilmektedir. Hem madde-toplam korelâsyonları hem de üst ve alt \%27'lik grupların madde ortalama puanlarına ilişin $t$-testi sonuçları ayırt ediciliği en yüksek olarak 6 . ve en düşük olarak 2. maddeyi göstermektedir. Ölçeğin güvenirliğini ortaya koymak amaciyla Cronbach Alfa iç tutarlılık katsayısı .82 olarak hesaplanmıştır. Bunun yanında madde-toplam korelâsyonlarının yüksekliği de ölçeğin iç tutarlılığının gücüne işaret etmektedir.

Özgün ve Türkçe ölçekte yer alan maddelerin faktör yapısına katkıları arasında farklılaşma olup olmadığını incelemek için her iki yapıdaki faktör yük değerleri karşılaştırmalı olarak ele alınmıştır. Bu durum Tablo 4'te ifade edilmektedir.

Tablo 4. Özgün ve Türkçe Ölçeklerin Faktör Yük Değerleri

\begin{tabular}{lll}
\hline Madde & Özgün Ölçekteki & Türkçe Ölçekteki \\
Numaras1 & Faktör Yük Değeri & Faktör Yük Değeri \\
\hline M1 & .77 & .60 \\
M2 & .69 & .50 \\
M3 & .80 & .60 \\
M4 & .68 & .62 \\
M5 & .80 & .72 \\
M6 & .84 & .84 \\
M7 & .79 & .71 \\
M8 & .83 & .55 \\
M9 & .69 & .48 \\
M10 & .73 & .63 \\
\hline
\end{tabular}

Hem özgün hem de Türkçe ölçekte en yüksek faktör yük değerini 6 . madde göstermektedir. Özgün ölçekte bunu 8,3 ve 5. maddeler, Türkçe ölçekte 5, 7 ve 10. maddeler izlemektedir. Özgün ölçekte en düşük faktör yük değerine sahip maddenin 4. ve Türkçe ölçekte 9. madde olduğu görülmektedir. Faktör yük değerleri arasındaki bu farklılaşma özgün ve Türkçe yapı arasında maddelere ilişkin genel katılım dereceleri açısından farklı1ıklar bulunduğunu ortaya koymaktadır. 


\section{Doğrulayıcı Faktör Analizi}

Tek faktörlü yapıya dönük olarak gerçekleştirilen doğrulayıcı faktör analizlerinde model üzerinde hiçbir sınama yapılmadan ve önerilen modifikasyonlar gerçekleştirilmeden önce ulaşılan uyum iyiliği indeksleri şöyledir: $\left[X^{2}(94)=88.48, \mathrm{p}=.00 ; X^{2} / d f=2.53 ; \mathrm{GFI}=.84 ; \mathrm{AGFI}=.75 ; \mathrm{CFI}=\right.$ $.88 ; \mathrm{NFI}=.82 ; \mathrm{NNFI}=.84 ; \mathrm{RMSEA}=.12 ; \mathrm{S}-\mathrm{RMR}=.09 ; \mathrm{IFI}=.88]$. Analizler sonucunda ortaya çıkan modifikasyon önerileri incelendiğinde; 9. ve 4 . madde arasında ve 9. ve 10. madde arasında iki önerinin ortaya çıktığı, bunlardan 9. ve 4. madde arasındaki önerinin modele daha yüksek katkı sağladığı görülmüsşür. Kuramsal olarak incelendiğinde 9. ve 4. maddenin çevrimiçi öğrenme ortamında ders görevleriyle ilişkili olmayan sohbet olanağına yönelik benzer durumları ölçtükleri, dolayısıyla iki madde arasında gizil bir ilişkinin kabul edilebilir olacağı görülmüş ve modifikasyon önerisi dikkate alınmıştır. Modifikasyonun ardından modele ilişkin uyum iyiliği indeksleri şu şekilde oluşmuştur: $\left[X^{2}(94)=67.92, \mathrm{p}<.01 ; X^{2} / d f=2.00\right.$; $\mathrm{GFI}=.87$; $\mathrm{AGFI}=.79 ; \mathrm{CFI}=.92 ; \mathrm{NFI}=.85 ; \mathrm{NNFI}=.89 ; \mathrm{RMSEA}=.10 ; \mathrm{S}-$ $\mathrm{RMR}=.08 ; \mathrm{IFI}=.92] . \mathrm{Bu}$ modifikasyonun ardından ulaşılan model yeni bir modifikasyon önerisi vermemiş, böylece analiz sonlandırılmıştır. Şekil 3'de tek faktörlü yapıya ilişkin yapısal eşitlik modeli ve Tablo 5'te ölçek maddelerine ilişkin $t$ ve $\mathrm{R}^{2}$ (çoklu korelâsyon katsayısı) değerleri sunulmaktadır.

Modelin uyum iyiliği indeksleri incelendiğinde, $X^{2} / d f$ değerinin 2.00 düzeyinde olduğu görülmektedir. Alanyazında bu değerin iki ve altında çıktığı modeller iyi modeller olarak nitelendirilmektedir (Şimşek, 2007: 14; Sümer, 2000). Öte yandan model uyumunun önemli bir göstergesi olan ve kabul edilebilir bir model için 90 seviyesinde değer göstermesi beklenen (Hair, Anderson, Tahtam ve Black, 1998: 657) GFI değeri .87 olarak bulunmuştur. Bulunan GFI değeri, eşik değerin altında kalmaktaysa da bu değere oldukça yakındır. Modelin AGFI ve NFI değerleri uygunluk için beklenen düzey olan .90 ve üzeri olma, RMSEA ise .08'in altında olma (Hair ve diğerleri, 1998: 660) koşullarını sağlayamamaktadır. Bununla birlikte, alanyazın irdelendiğinde bu indekslerin aldıkları değerlerin örneklem büyüklüğünden etkilenebildikleri (Şimşek, 2007: 48) görülmektedir. Araştırma grubunun doğrulayıcı faktör analizleri için uygun aralık kabul edilen 200'ün (Kline, 2000b: 73) oldukça altında olması nedeniyle örneklem büyüklüğü etkilerinden arındırılmış uyum iyiliği indekslerinin incelenmesinin daha sağl1klı sonuçlar ortaya koyabileceği düşünülmüş, bu amaçla CFI ve IFI üzerinde durulmuştur. Bu indeksler için .90 seviyesi üzerinde değerler modelin kabul edilebilir olduğunu göstermektedirler (Şimşek, 2007: 48; Sümer, 2000). Burada tek faktörlü yap1 için her iki 
indeks de .92 seviyesinde değer alarak modelin kabul edilebilirliğine işaret etmektedir. Yapısal eşitlik modelinde gizil değişkenleri gözlenen değişkenlere bağlayan standardize edilmiş değerler $\lambda_{\mathrm{x}}$ (Lambda-x) olarak adlandırılmakta ve ilgili gözlenen değişkenin gizil değişken açısından önemini ortaya koymaktadırlar (Şimşek, 2007: 85). Bu değerler incelendiğinde tüm gözlenen değişkenlerin gizil değişkenin ölçümüne olumlu yönde katkı sağladığı görülmektedir. Elde edilen $t$ değerleri ise her bir gözlenen değişkenin gizil değişken tarafindan ne derece anlamlı yordandığını ortaya koymaktadır; .05 anlamlılık düzeyi için eşik $t$ değeri 1.96, .01 anlamlılık düzeyi için ise 2.576'dır (Şimşek, 2007: 86). Modele ilişkin $t$ değerleri incelendiğinde tüm gözlenen değişkenlerin gizil değişken tarafindan .01'lik anlamlılık düzeyinde yordanabildiği görülmektedir. Önemli bir ölçüt de her bir gözlenen değişken için açıklanan varyansı ifade ederek, gözlenen değişkenin gizil değişkendeki değişimin ne kadarını açıklayabildiğini ortaya koyan $\mathrm{R}^{2}$ değeridir (Şimşek, 2007: 86). Modele ilişkin $\lambda_{x}, t$ ve $R^{2}$ değerleri incelendiğinde algılanan sosyalleşmenin ölçümüne en yüksek katkıyı 6. maddenin en düşük katkıyı 9. maddenin sağladığı görülmektedir. Bu bulgu, açımlayıcı faktör analizinde elde edilen bulguları doğrulamaktadır.

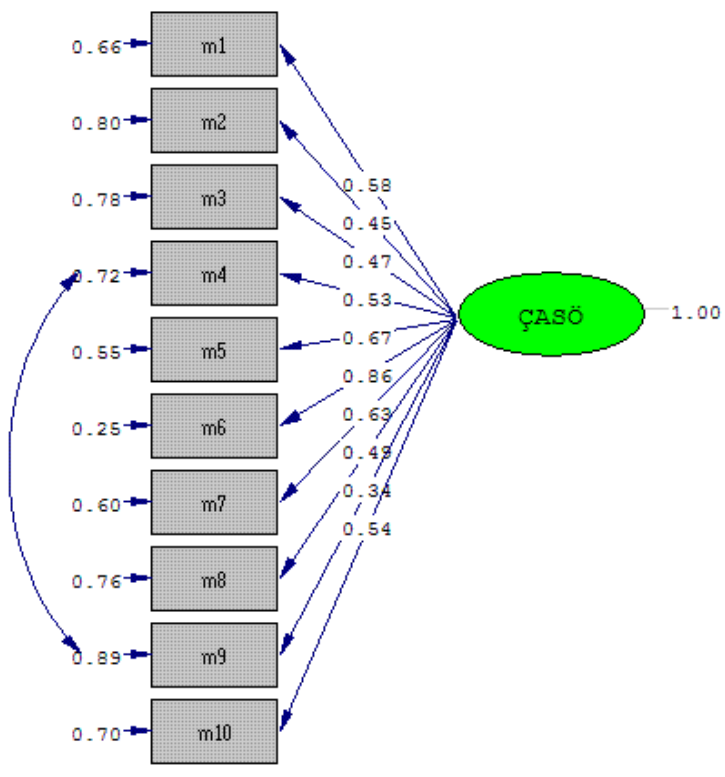

Chi-Square $=67.92, d f=34, P-$ value $=0.00048$, RMSEA $=0.104$

Şekil 3. ÇASÖ Yapısal Eşitlik Modeli ve Standart Değerleri 


\begin{tabular}{llc}
\multicolumn{3}{c}{ Tablo 5. ÇASÖ Maddelerine Ilişkin t ve $R^{2}$ Dĕ̌gerleri } \\
\hline $\begin{array}{l}\text { Madde } \\
\text { Numaras1 }\end{array}$ & $t$ & $\mathrm{R}^{2}$ \\
\hline M1 & 5.73 & .34 \\
M2 & 4.27 & .20 \\
M3 & 4.50 & .22 \\
M4 & 5.10 & .28 \\
M5 & 6.86 & .45 \\
M6 & 9.75 & .75 \\
M7 & 6.40 & .40 \\
M8 & 4.76 & .24 \\
M9 & 3.10 & .11 \\
M10 & 6.37 & .30
\end{tabular}

\section{SONUÇ}

$\mathrm{Bu}$ araştırmada Kreijns, Kirshner, Jochems ve Buuren (2007) tarafindan bilgisayar destekli ortaklaşa öğrenme ortamlarına yönelik olarak geliştirilen Algılanan Sosyalleşme Ölçeği'nin geçerlik ve güvenirlik çalışmaları bir Türk örneklem grubu üzerinde çevrimiçi öğrenme ortamlarına yönelik olarak gerçekleştirilmiştir. Bu süreçte öncelikle ölçek Türkçeye çevrilmiş, ardından bir Türkçe ve yedi eğitim teknolojisi alan uzmanının görüşleri alınarak her bir maddenin dilimizde özgün anlamına en yakın anlamı taşıması için gerekli düzenlemeler yapılmıştır. İngilizce ve Türkçe yapılar arasında dilsel eşdeğerlik sağlandıktan sonra, ölçek 94 kişilik bir gruba uygulanmıştır. Ölçek çevrimiçi öğrenme deneyimlerine ilişkin ifadeler içerdiğinden çalışma grubunun belirlenmesinde 2007-2008 öğretim y1lında bir çevrimiçi öğrenme deneyimi yaşamış olma ölçütü dikkate alınmıştır.

Yapı geçerliği çalışmalarında Türkçe ölçekte yer alan on maddenin istatistiksel olarak hem iki hem de tek faktörlü yapı gösterebildiği; ancak iki faktörlü yapının kuramsal olarak anlamlı olmadığı belirlenmiş; maddelerin tek faktör yapısı altında incelenmesi yoluna gidilmiştir. Bu yap1, özgün ölçeğe benzer biçimde, tek faktör altında ölçekte yer alan on maddeyi kapsamakta ve toplam varyansın \%40.11'ini açıklamaktadır. Bu oran tek faktörlü ölçek yapısı için yeterli bir düzeydedir. Madde analizlerinde, madde-toplam puanları arasında güçlü bir korelasyonel ilişki belirlenmiş ve Cronbach Alfa iç tutarlılık katsayısı .82 olarak hesaplanmıştır. Hem maddetoplam korelâsyonlarından hem de iç tutarlılık katsayısından hareketle uyarlanan ölçeğin güvenilir olduğu düşünülmektedir. Özgün ve Türkçe ölçeğe ilişkin faktör yük değerleri karşılaştırıldığında en yüksek değeri gösteren 6. madde haricinde, yük değeri sıralamasında farklılaşmalar olduğu görülmektedir. Bu durumun her iki çalışmada yer alan katılımcı gruplarının 
sahip oldukları kültür ve çevrimiçi öğrenme deneyimleri arasındaki farkl11ıklardan kaynaklandığı düşünülmektedir.

Doğrulayıcı faktör analizinin ortaya koyduğu uyum iyiliği indeksleri ve standart değerler açımlayıcı faktör analiziyle ortaya konan tek faktörlü yapının uygunluğuna işaret etmektedir. Özellikle $X^{2} / d f$, CFI ve IFI değerleri yapının kabul edilebilir düzeyde olduğunu ortaya koymaktadır. GFI, NNFI ve S-RMR değerleri ise kabul edilebilirlik düzeylerine oldukça yakın değerler almaktadırlar. Öte yandan, AGFI, NFI ve RMSEA indeksleri, yakın olmakla birlikte kabul edilebilirlik sınırlarının dışında değer göstermektedirler. Bu noktada bir sınırlılık olarak araştırmanın örneklem büyüklüğü üzerinde durmak gerekmektedir. Bilindiği gibi doğrulayıcı faktör analizlerinde sağlıklı uyum değerleri üretilebilmesi için önerilen örneklem büyüklüğü 200 civarındadır (Kline, 2000b: 73). Ancak uygulama çalışmalarının çevrimiçi öğrenme deneyimlerine sahip bir grup üzerinde gerçekleştirilmesi gerekliliği ve bu niteliği taşıyan örnekleme ulaşmaktaki sınırlılıklar nedeniyle araștırmada 94 katılımcıya erișilebilmiştir. Alanyazın incelendiğinde RMSEA, AGFI, NFI gibi indekslerin örneklem büyüklügü̈nden etkilenebildikleri görülmektedir (Şimşek, 2007: 48). Dolayısıyla doğrulayıcı faktör analizinde kabul edilebilirlik sınırı altında değer gösteren bu indekslerin araştırma grubunun sınırlılığından etkilenmiş olabilecekleri düşünülmektedir.

Araştırmada bir sınıllılık olarak özgün ölçeğe ilişkin geliştirme çalışmalarının farklı bölümlerde öğrenim görmekte olan üniversite öğrencileri üzerinde, uyarlama çalışmalarının ise BÖTE bölümünde öğrenim görmekte olan üniversite öğrencileri üzerinde uygulanmış olması ele alınabilir. Bu durum çevrimiçi öğrenme deneyimlerine sahip öğrenenlerin BÖTE bölümlerinden sağlanabilmesinden kaynaklanmıştır. Özgün ve Türkçe ölçeğe ilișkin faktör yük değerleri, iç tutarlılık katsayıları gibi istatistiksel parametrelerdeki birtakım değişimlerde çalışma gruplarındaki bu farklılığın da etkili olabileceği düşünülmektedir. Bununla birlikte çalışma grubunun küçüklügü ä̧ımlayıcı faktör analiziyle elde edilen değerleri de etkileyebilecek bir sinırlılık olarak ele alınabilir. Gelecekte farklı alanlardan çevrimiçi öğrenme deneyimlerine sahip ve daha geniş katılımcı grupları üzerinde ölçeğin faktör yapısının yeniden sorgulanmasının yararlı olacağ düşünülmektedir.

Güven ve bağlılık duygularının gelişmesine, topluluğa uyum sağlama ve etkin katılım süreçlerine ve bunlarla ilişkili olarak öğrenmenin etkililiğine etkileri göz önüne alındığında katılımcıların topluluğun sosyalleşme olanaklarına ilişkin algılamalarının çevrimiçi öğrenme topluluklarının etkililik, verimlilik ve çekiciliklerinin arttırılmasında dikkate alınması 
gereken bir etken olduğu görülmektedir. Bu durum ÇASÖ’yü ülkemizde çevrimiçi öğrenme topluluğu geliştirme süreçlerinde kullanılabilecek işlevsel bir araç olarak öne çıkarmaktadır.

\section{KAYNAKLAR}

Barab, A. S., MaKinster, J. G., Moore, J. A., \& Cunningham, D. J. (2001). Designing and building an on-line community: the struggle to support sociability in the inquiry learning forum. Educational Technology researc \& Development, 49 (4), 71-96.

Büyüköztürk, Ş. (2006). Sosyal Bilimler İçin Veri Analizi El Kitabı. Istatistik, Araştırma Deseni SPSS Uygulamaları ve Yorum (6. baskı). Ankara: Pegem A yayıncilik.

Büyüköztürk, Ş. (2002). Faktör Analizi: Temel Kavramlar ve Ölçek Geliştirmede Kullanımı. Kuram ve Uygulamada Eğitim Yönetimi, 32, 47-483.

Donath, J. S. (1997). Inhabiting the virtual city: The design of social environments for electronic communities. Unpublished doctoral dissertation, Massachusetts Institute of Technology. [Online]: Retrieved on 3-July-2008, at URL: http://smg.www.media.mit.edu/people/judith/ Thesis/ThesisContents.html.

Farnham, S., Zaner, M., \& Cheng, L. (2001). "Supporting sociability in a shared browser." Paper presented at the Interact Conference, Tokyo, Japan

Hair, J. F., Anderson, R. E., Tahtam, R. L., \& Black, C. W. (1998). Multivariate Data Analysis (5th Edition). New Jersey: Prentice Hall.

Hassanein, K., \& Head, M. (2004). "Instilling social presence trough the web interface." Paper presented at the Third Annual Workshop on HCI Research in MIS, Washington D.C, USA

Hobaugh, C. F. (1997). Interactive strategies for collaborative learning. In Proceedings of the Annual Conference on Distance Teaching and Learning: Competition Connection-Collaboration (pp. 121-125) University ofWisconsin-Madison, USA.

Kalaitzakis, E., Dafoulas, g. \& Macaulay, L. (2003 ). "Designing online communities: Community-centered development for intensively focused user groups." Paper presented at the 10th HCI International Conference (HCII 2003), Heraklion, Greece. 
Kline, P. (2000a). The Handbook of Psychological Testing (2nd Edition). London and Newyork: Routledge.

Kline, P. (2000b). An Esay Guide to Factor Analysis (4th Edition). New York: Routledge.

Kline, P. (1994). An Esay Guide to Factor Analysis. New York: Routledge.

Kreijns, K. (2004). Sociable CSCL Environments Social Affordances, Sociability, and Social Presence. Maastricht: Datawyse boek-en Grafische Producties. [Online]: Retrieved on 1-Jully-2008, at URL: [Online]: http://www.ou.nl/eCache/DEF/13/252.html

Kreijns, K., Kirschner, P. A., \& Jochems, W. (2002). The sociability of computer-supported colaborative learning environments. Journal of Educational Technology \& Society, 5(1), 8-22. [Online]: Retrieved on 2-Jully-2008, at URL: http://www.ifets.info/journals/5_1/kreijns.pdf.

Kreijns, K., Kirschner, P. A., Jochems, W., \& VanBuuren, H. (2007). Measuring perceived sociability of computer- supported colloborative learning environments. Computers \& Education 49, 176-192.

Lazar, J., \& Preece, J. (2003). Social considerations in online communities: Usability, sociability, and succes factors. In H. Vanoostendorp (Ed.), Cognition in a Digital World (pp: 127-151). New Jersey-London: Lawrence Erlbaum.

Nie, N. H. (2001). Sociability, interpersonal relations, and the internet. American Behavioral Scientist, 45 (3), 420-435.

Preece, J. (2000). Shaping communities: emphaty, holisty, lurking, participation. In Proceedings of CPSRDIA2000, Shaping the Network Society: The Future of the Public Shape in CyberSpace (pp. 25-34), Seattle, USA.

Preece, J. (2001a). Sociability and usability in online communities:Twenty years of chatting online. Behaviour \& Information Technology 20 (5), 347-356.

Preece, J. (2001b). "Designing usability, supporting sociability: Questions participants ask about online communities." Paper presented at Human Computer Interaction INTERACT 01, Tokyo, Japan.

Preece, J. (2003). Tacit knowledge and social capital: Supporting sociability in online communities of practice. In Proceedings of I-KNOW'03, $3 r d$ International Conference on Knowledge management. In $\mathrm{K}$. Tochtermenn and H. Maurer (Eds.), 72-78. Graz, Austria. 
Preece, J. (2007). Sociability and usability in online spaces (Luncheon Keynote). Paper presented at The 2007 International Symposium on Colloborative Technologies and Systems (CTS'07), Orlando, Florida, USA.

Rheingold, H. (1994). A slice of my virtual community. In L. M. Harasim (Ed.), Global Networks: Computer and International Communication (pp: 57-80). Cambridge: MIT Press.

Ritzer, G. (1992, Çev: Ümit Tatlıcan). Sociological Theory (3rd Edition). McGraw Hill. [Online]:http://www.umittatlican.com/files/ Yapisal\%20Marksizm\%20(George\%20Ritzer,\%201992).pdf adresinden 10 Temmuz, 2008 tarihinde indirilmiştir.

Öztürk, E. (2008). Toplumsal Yetenek Ölçeği Geçerlik ve Güvenirlik Çalışması. Ankara Üniversitesi Eğitim Bilimleri Fakültesi Dergisi, 41 (2), $97-120$

Simmel, G. (1949, Çev:Everett C. Hughes). The sociology of sociability. The American Journal of Sociology 55(3), 254-261

Sümer, N. (2000). Yapısal Eşitlik Modelleri: Temel Kavramlar ve Örnek Uygulamalar. Türk Psikoloji Yazıları, 3(6), 49-74

Şimşek, Ö. F. (2007). Yapısal Eşitlik Modellemesine Giriş Temel İlkeler ve LISREL Uygulamalar1. Ankara: Ekinox

Tu, C. H. (2000). On-line learning migration: From social learning theory to social precence theory in CMC environment. Journal of Network and Computer Application, 23 (1), 27-37.

Volet, S., \& Wosnitza, M. (2004). Social affordances and students' engagement in cross national online learning. Journal of Research in International Education, 3 (1), 5-29.

Zwick, W. R., \& Velicer, W. F. (1986). Comprasion of five rules for determining the number of components to retain. Psychological Bulletin, 99(3), 432-442. 


\section{EK 1}

The Perceived Sociability Scale of Computer-Supported Collaborative Learning Environments (Kreijns, Kirschner, Jochems and Buuren, 2007)

01. This CSCL environment enables me to easily contact my team mates

02. I do not feel lonely in this CSCL environment

03. This CSCL environment enables me to get a good impression of my team mates

04. This CSCL environment allows spontaneous informal conversations

05. This CSCL environment enables us to develop into a well performing team

06. This CSCL environment enables me to develop good work relationships with my team mates

07. This CSCL environment enables me to identify myself with the team

08. I feel comfortable with this CSCL environment

09. This CSCL environment allows for non-task-related conversations

10. This CSCL environment enables me to make close friendships with my team mates

\section{EK 2}

Çevrimiçi Öğrenme Ortamında Algılanan Sosyalleşme Ölçeği

01. Bu çevrimiçi öğrenme ortamı grup arkadaşlarımla kolayca iletişim kurmama olanak sağlamaktadır.

02. Bu çevrimiçi öğrenme ortamında kendimi yalnız hissetmiyorum.

03. Bu çevrimiçi öğrenme ortamı grup arkadaşlarım hakkında iyi bir izlenim edinmeme olanak sağlamaktadır.

04. Bu çevrimiçi öğrenme ortamı kendiliğinden gelişen gündelik sohbetlere izin vermektedir.

05. Bu çevrimiçi öğrenme ortamı yüksek performanslı bir grup oluşturmamıza olanak sağlamaktadır.

06. Bu çevrimiçi öğrenme ortamı grup arkadaşlarımla iyi çalışma ilişkileri geliştirmeme olanak sağlamaktadır.

07. Bu çevrimiçi öğrenme ortamı kendimi içerisinde bulunduğum grubun üyesi olarak tanımlamama olanak sağlamaktadır.

08. Bu çevrimiçi öğrenme ortamında kendimi rahat hissetmekteyim.

09. Bu çevrimiçi öğrenme ortamı ders görevleriyle ilişkili olmayan sohbetlere izin vermektedir.

10. Bu çevrimiçi öğrenme ortamı grup üyeleriyle yakın arkadaşlıklar kurmama olanak sağlamaktadır. 
